\title{
A NEW PARADIGM FOR THE NEXT CENTURY: THE TASK ORIENTED JOB MARKET
}

\author{
Marcelo Moretti Fioroni ${ }^{1}$, Antônio Batocchio ${ }^{2}$ \\ DEF/FEM/UNICAMP; Caixa Postal 6122, CEP: 13083-970, Campinas/SP, BRAZIL \\ Tel: (019) 788-3290; Fax: (019) 289-3722; E-mail:mfioroni@mii.zaz.com.br ${ }^{I}$, \\ batocchi@fem.unicamp.br ${ }^{2}$
}

\begin{abstract}
In a society that becomes more and more integrated with the technology and its benefits, the changes can be noted everywhere, including on the job market. When the society becomes more digital, the same happens with the jobs and employs, and while the technology brings to us new necessities, it also provides the ways we can reach them. Things like Telework and Telecommuting are going to be common ways of work on the near future. But all this connected legion requires a new way of interaction and market approach, a way that can be provided from Holonic Manufaturing Architecture studies. The ways on how the Holonic architecture can organize that new job market are the objective of the present study.
\end{abstract}

\section{INTRODUCTION}

The new state of economy and market nowadays are a well-known fact. Things like low price and high quality have became a commodity, and the consumers now demand for availability and customization. The consequences for manufacturing industry are deep and it requires a change from the "scale economy" to the "scope economy" (Kidd, 1994).

Looking for the manufacturing system that can satisfy the requirements of the market for the next century, some countries have joined efforts to research such systems, on a consortium called "Intelligent Manufaturing Systems Consortium" (IMSC Home Page, 1999). It is a closed group congregating great companies, universities and research institutes located in these countries, acting under some research proposals. One of these proposals is the Holonic Manufacturing System, a system that can reach the optimum use of its resources, become stable in face of disturbances, and be adaptable and flexible in face of change. An architecture for Holonic Manufacturing Systems was presented by Jo Wyns (1999), called PROSA Product Resource Order Staff Architecture.

As the technologies advance and the microcomputers become cheaper and cheaper and powerful, the society becomes "digital", forging a new environment for business and expanding possibilities. The Telework is one of these possibilities (Mello, 1997). 
Another factor that must be considered on the job market nowadays is the continuous growth of the unemployment statistics. These phenomena are well described by Bridges (1996) and Rifkin (1996), and the consequences are more and more people acting as freelance or as "one-person company" at SOHOs (Small Office Home Offices).

Applying the PROSA architecture to the environment provided by the Internet and microcomputers, we can get a way to coordinate all these factors on a positive way. On the following sections, the topics mentioned here will be detailed and joined, reaching the "Task Oriented Job Market".

\section{THE HOLONIC MANUFACTURING SYSTEM AND THE PROSA ARCHITECTURE}

As mentioned above, the Holonic Manufacturing System is a research theme of the IMS Consortium. The word "Holonic" comes from "Holon", that was first proposed by Arthur Koestler (1989) and it is a combination from the Greek Holos, that means "whole", with the suffix -on that suggests a particle or part (like "eletron", or "proton"). The concept of Holon describes something that is simultaneously selfcontained wholes to their subordinated parts, and dependent parts when seen from the inverse direction (Wyns, 1998). As observed by Koestler, when small structures that are stable and self-contained join together, the resulting structure is stable and self-contained too.

The Holonic Manufacturing System (HMS) has the goal to attain in manufacturing the benefits that Holonic organizations provide to living organisms and societies: stability in the face of disturbances, adaptability and flexibility in the face of change and efficient use of available resources (Wyns, 1998).

The proposed architecture for HMS is called PROSA (Product Resource Order Staff Architecture), because it defines three basic holons: Product Holon, Resource Holon and Order Holon, and a support/helper holon called Staff Holon (Wyns, 1999).

The three basic holons are described below:

- Product Holon: It has the function to congregate all information about the product itself, its quality level, process plans, materials needed, lifetime and others. It acts as the "central information" for the other holons;

- Resource Holon: It is the physical part of the system, including machines, people, energy supply, etc. It provides production capacity for the other holons;

- Order Holon: It represents a task inside the production system. It manages the physical product being produced, the product state model and all related logistical information. The Order Holon can represent a customer order, make-to-stock orders, orders to maintain or repair resources, etc.

The relationship between the three basic holons is represented at Figure 1.

In addition, we have the Staff Holon. This Holon can accomplish specific tasks that could not be made from the basic holons with the same efficiency. Despite its efficiency, the Staff Holon is too specialized and not very flexible. So, when some 
change or problem happens, the task goes to the basic holons, instead of the Staff Holon.

This architecture decouples the agility and robustness of the system from its optimization, providing the benefits of both hierarchical and heterarchical systems, without these disadvantages.

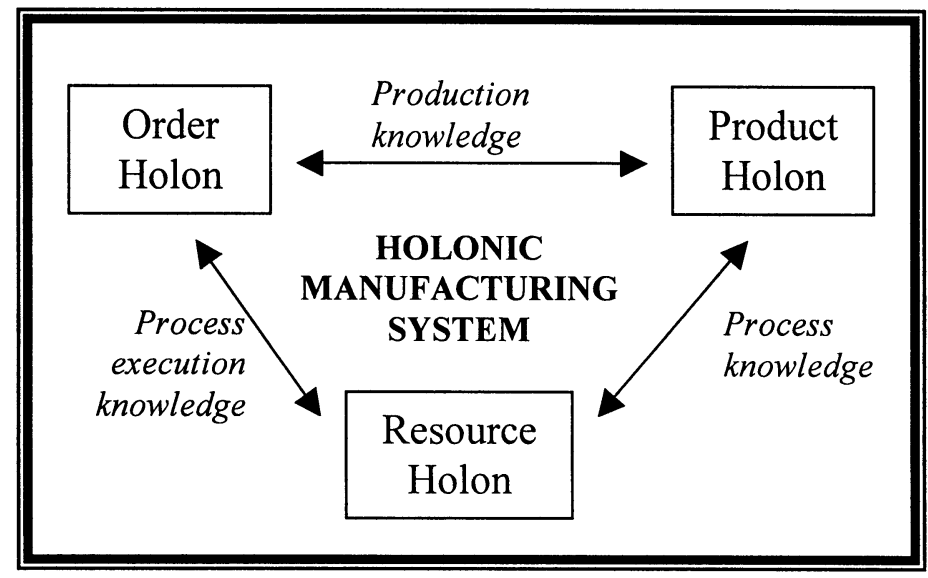

Figure 1: The PROSA Architecture (Wyns, 1999)

\section{THE "DIGITAL SOCIEY", TELEWORK AND "SOHO"}

Nowadays, we can observe a few phenomena in our society:

- The newest technologies become available for a growing number of people, and the popularization of the Internet stimulates everyone to join it, to shop, communicate and even work;

- This technology popularization has created new necessities and kinds of job. As the microcomputers acquire relevance, the related areas become more relevant too: software development, new systems, new services for computer users, etc. (Tappscott, 1995);

- The advances on management techniques and automation systems qualify the big companies to produce better with less employees. It makes grow the unemployment statistics all over the world (Rifkin, 1996);

- The entire-life kind of employ was gone. Nowadays, the relationship between employer and employees have changed from the paternalism and fidelity to the infidelity from both sides. The professionals are looking for better proposals all the time, and the companies stop to offer the traditional benefits to offer stocks or participation on the results. It happens because the employees become more stimulated if working for something to their own (Bridges, 1996).

Joining the unemployment, the desire to work for something to their own and the technology availability, we have a strong tendency to the formalization of SOHO: small companies that works on small offices or home offices, with one or a few people working. 
The technology also brings us the Telework: a kind of work where the employee does not need to be physically at the company. He can work at home, using a computer connected or not on the company's system (Mello, 1997). The telework implies on many consequences to both sides, some positive and some negative, many of them described by Lima (1999). It requires a change on the way people think and on the way companies manage their employees (Nilles, 1998).

On a hybrid situation, the SOHO companies can use the same infrastructure of the telework to work or sell services to the big companies, or even join efforts to reach a common objective.

\section{THE HOLONIC GROUPING}

As proposed by Fioroni (1999), the PROSA architecture can be used by a group of small companies (SOHOs) to organize themselves on a bigger structure, capable to realize much more than their components individually. This kind of group was called "Holonic Grouping", and it considers each small company as an Holon, because each of them is self-contained and stable. Each Holon of the grouping is described below:

- Order Holon: One person or company wants to act as Order Holon, representing the customer desires in face of the rest of the grouping. He's responsible to take care that the product will be made as the customer wants and on time. He provides information about what the customer wants for the Product Holon and monitors the Resource Holon.

- Product Holon: It's an information central, where the information about the product is stored. It can be a computer server connected to the Internet, and accessed by the other Holons (small companies) to exchange information. This computer can be managed by another small company, that "sells" the "Product Holon service".

- Resource Holon: It's the equipment, person and infra-structure involved on the execution of the work. It can be an small company that "do the job".

- Staff Holon: It's a small company that join the group when a more specific job has to be done.

Basically, the Holonic Grouping acts this way: a small company finds a job (a task to be done to a customer) that cannot be done alone. That company becomes the "Order Holon", calling for the services of a "Product Holon" company and providing the required information to it. Also, it calls for a service of a "Resource Holon" company, or acts itself as the Resource Holon, if it's capable to do it. If the job involves some specific necessity, a company capable to provide it is called to act as the Staff Holon.

This organization provides the advantages of Holonic Systems:

- Stability in face of change: The Holonic Grouping can easily modify its structure to support new situations. An example: if the grouping is doing some job, and the customer wants to change the size of the work, or another customer have appeared, the grouping can increase its capacity aggregating more Resource Holons; 
- Flexibility and adaptability in face of disturbances: The flexibility of the grouping is total. If some change happens on the market, the grouping can "disconnect" the unnecessary Holons and "aggregate" new Holons that can do the job. The Figure 2 presents this functionality;

- Efficient use of the available resources: The capacity to connect and disconnect Holons grants that the grouping is e er working with the exact capacity required to do the job.

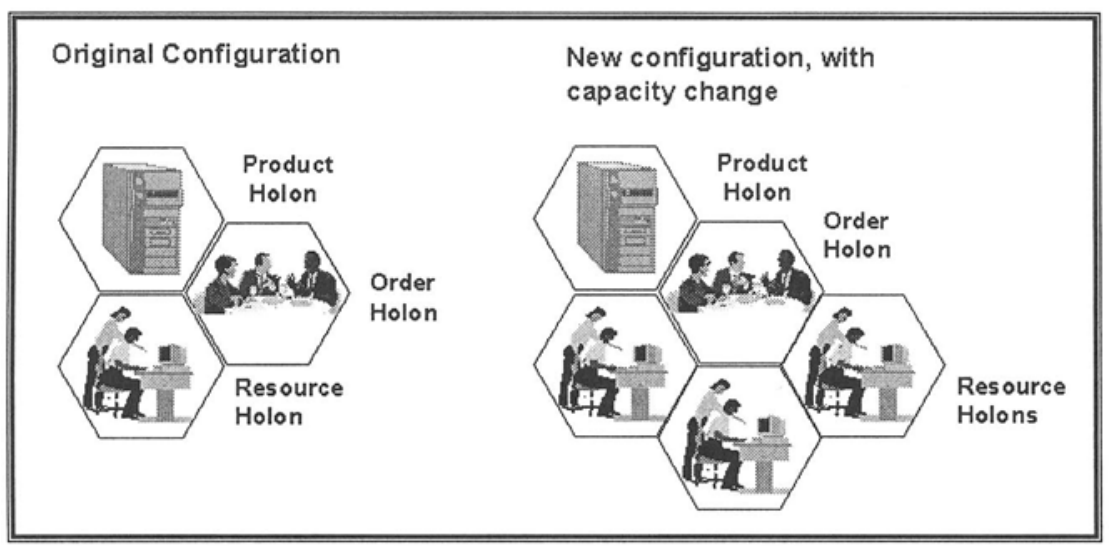

Figure 2 - The Holonic Grouping changing its configuration

The Holonic Grouping is a fundamental piece to reach the Task Oriented Job Market.

\section{THE TASK ORIENTED JOB MARKET}

Under a simplified way, the job market can be "polarived" on two sides:

- Tasks: Companies or people that ha e a job to be made, as a product, a ser ice, a new necessity of the market that wants to be satisfied researching a new kind of product. It can be defined as "customers";

- Workers: Big, medium or small companies, or freelance professionals that can work on those tasks and accomplish them.

Just like the poles of an energy battery, whose poles attract themsel es (the customers look for someone that can be the tasks, and the workers look for a job). When the contact occurs, the money flows from one side to another, just like the electrons on an energy battery.

At our present situation, we ha e many "resistances" between the both poles, obstacles that make this contact more difficult and e en "isolate" the poles. Things like bureaucracy, high costs of the employees, decentralived information about a ailable tasks and workers, physical distance and many other factors can difficult that contact. If all or many of these obstacles could be remo ed, we can ha e a "superconductor", a situation where the tasks are promptly accomplished by the a ailable workers. The Figure 3 graphically represents both situations. 


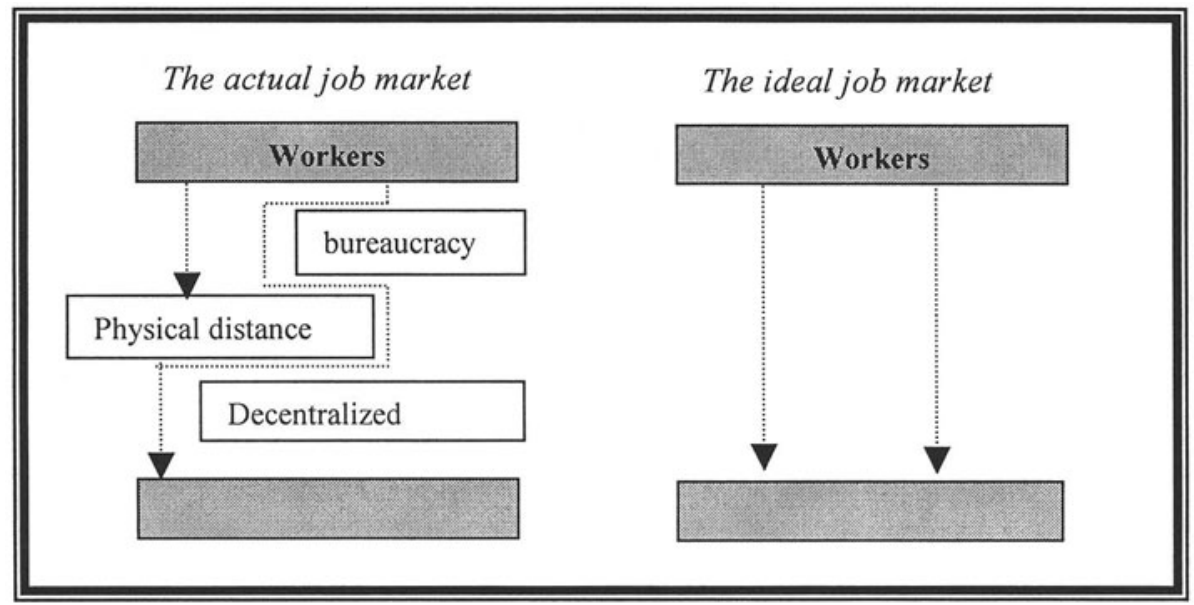

Figure 3 - Both situations for the job

The Holonic Grouping, working on the correct en ironment, can contribute a lot to connect the Tasks to the Workers. Those en ironment can be called "Task Oriented Job Market", because it is acti ated by the tasks.

The key for Holonic Grouping is exactly that en ironment, because the Grouping is not possible if we ha e just a few Holons. The flexibility could be seriously harmed on those situations. With the high a ailability of many different Holons, a di ersified combination of resources and skills can be obtained, assisting e ery task possibility.

So, if we consider each Holon as a small company, we ha e a job market with a lot of small companies running under a big communication infrastructure that remo es the physical distance between them and enables its union. Yes, we already ha e it! The small companies formalivation are growing and the Internet too. But e erything must be organived on the correct way to become "task oriented".

That organivation can be pro ided from a Holonic System property: an Holon can be part of another Holon. In other words, all those Holons (small companies) are part of a bigger Holon that organive and coordinate their actions, pro iding aluable information to associate the workers to the corresponding tasks.

In a practical way, we ha e the following situations:

- A set of standards to establish the communication among the companies and with the "bigger Holon", that coordinates their actions. It is necessary to keep the pri acy of the information flow;

- A central database that keeps information about the present a ailable tasks. That database works just like a bigger Order Holon. When a customer has a task, he has the option to submit it to that central Order Holon, instead of looking for a worker for himself.

- The small Holons has the option to look for a task at the central Order Holon described abo e. When a task is "adopted", it is remo ed from the central Order Holon and it goes to the small Order Holon, starting the procedures to work on it, acti ating the Resource and Product Holons. 
- The "bigger Holon" has the function to provide valuable information to its component Holons, but has not the power to order his actions. The Holons have the freedom to use or not the available information structure. The Figure 4 illustrates some of these concepts.

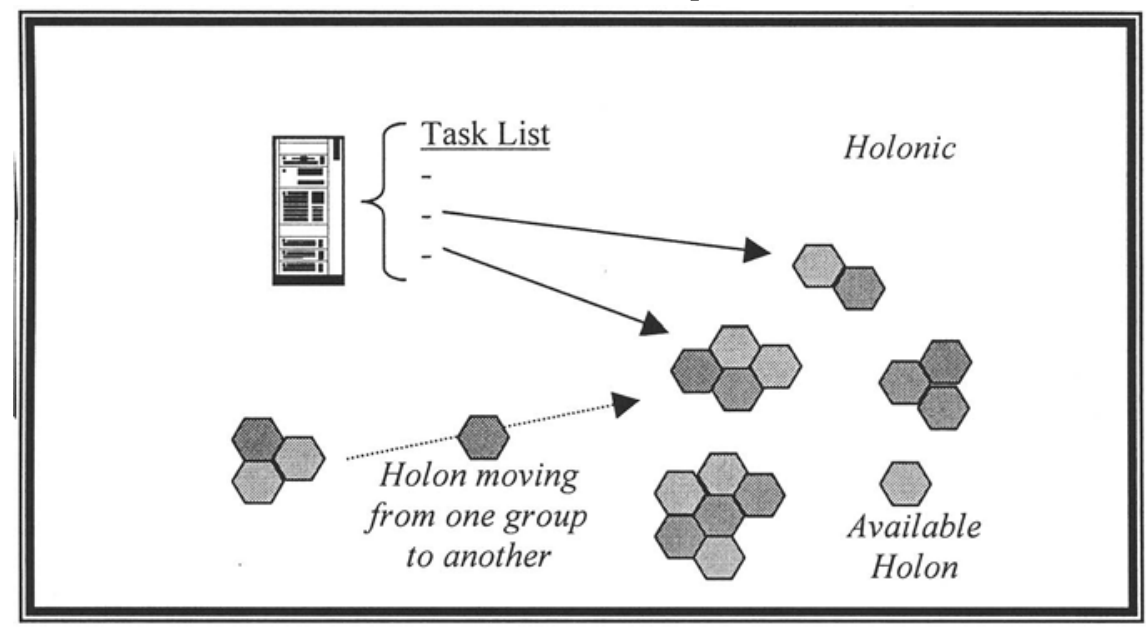

Figure 4 - The task oriented iob market

The logical candidate to act as the central Order Holon is the government, but it could even be a service provided from some company, or many companies (another Holonic Grouping). And the limitations of all this structure are the country or the province. In the future, as the globalization advances, the entire world will be able to work this way without frontiers.

Of course the proposed structure has its limitations and problems:

- It's restricted to computer software related products, as multimedia creations, simulation projects, software systems and every product that can be developed using computers or be converted to the computer format (like movies, music or documents). Of course this kind of product has grown too, following the microcomputers popularization;

- If we have more tasks than available Holons or an excess of available Holons, we have a problem. At the first situation, the tasks will remain waiting a long time to be worked, and at the second, we have the traditional unemployment.

- The customers usually must trust on workers that will work on his tasks, and they don't want to have it done by "anyone". This can be solved creating some kind of "Holon Certification", where just the certified Holons have access to the tasks database.

\section{CONCLUSIONS}

On a comparison with the human organism defense system, the Task Oriented Job Market has the Holons acting like the antibodies. When an strange element enters inside the human body, the antibodies immediately attack it. If the element is big or 
numerous, more antibodies are in oked to remo e all strange elements. The same happens with the tasks inside the proposed job market: the Holons work to accomplish the task, and if it is big or numerous, the Holon increases its capacity in oking other Holons.

As mentioned abo e and still using the human body comparison, the insufficiency of antibodies to attack the strange elements becomes a serious infection, and the excess of antibodies becomes an allergic reaction. Both situations are bad to the organism. The same happens on the job market when the number of Holons is excessi e or insufficient. Being more clear, an insufficient number of holons to do the job will cause an unexpected delay to finish the task, and the customer will not recei e the product on time. And if we ha e an excessi e number o holons, we ha e the nowadays well know problem: the unemployment.

Showing a practical situation, a customer has a computer system to be de eloped. He register what he need at the Order Holon, that immediately start to search on its database for the a ailable companies or people (Resource Holons) that can do the job. After a brief "negotiation" between the Order Holon and the Resource Holons, one or some of them are selected to work on that task. The companies selected (Resource Holons) make contact with the customer to gi e details about the product and keep the Order Holon informed about each step of the de elopment. When the Order Holon detects that the job will not finish on time, it selects more Resource Holons to join efforts and enlarge the total capacity.

Instead of its limitations, the proposed job market fits the en ironment of business and market for the next century, where the agility is a pre-requisite to all companies that intend to sur $\mathrm{i}$ e.

\section{ACKNOWLEDGEMENTS}

The authors are grateful to FAPESP that sponsors one of the authors, and to RECOPE/FINEP/BID by the computer resources that made this job possible.

\section{REFERENCES}

1. Bridges, W. - Um mundo sem Empregos - Jobshift. Makron Books, São Paulo, 1996.

2. Fioroni, M. M., Batocchio, A. - Empresas com Arquitetura Holônica: Uma solução para o mercado de trabalho do próximo milênio. VI Simpósio de Engenharia de Produção - SIMPEP, Fac. Eng. Mec. UNESP, Bauru, SP, 8-10 nov. 1999.

3. Kidd, P.T. - Agile Manufacturing - Forging New Frotiers. Addison-Wesley Publishing Company, England, 1994.

4. Koestler, A. - The Ghost in the Machine. Arkana Books, London, 1989.

5. Lima, F. U.. - Teletrabalho: Perspectivas sobre produtividade e emprego. VI Simpósio de Engenharia de Produção - SIMPEP, Fac. Eng. Mec. UNESP, Bauru, SP, 8-10 nov. 1999.

6. Mello, A. - Teletrabalho. Qualitymark, São Paulo, 1997.

7. Nilles, J. M. - Managing Telework: Strategies for Managing the Virtual Workforce. John Wiley \& Sons, New York, 1998.

8. Rifkin, J. - O Fim dos Empregos. Makron Books, São Paulo, 1996.

9. Wyns, J., Langer, G. - Holonic Manufacturing Systems described in plain text, IDEF0, and ObjectOriented methods. Proceedings of IMS-Europe, Lausanne, 15-17 april 1998, pp. 13-28.

10. Wyns, J. - Reference Architecture for Holonic Manufacturing Systems - The key to support evolution and reconfiguration. Belgium: KULeuven, 1999. Doctoral Thesis, Katholieke Universiteit Leuven. 